\title{
Statistics for industries: A sophisticated approach
}

\author{
Prabhakar Kaushik $^{a^{*}}$, Vijay Kumar Dahiya ${ }^{b}$ and Kapil Mittal ${ }^{c}$
}

${ }^{a}$ Associate Professor, Department of Mechanical Engineering, UIET, Maharshi Dayanand University, Rohtak, Haryana, India

${ }^{b}$ Lecturer, Department of Mechanical Engineering, Government Polytechnic Meham, Rohtak, Haryana, India ${ }^{c}$ Assistant Professor, Department of Mechanical Engineering, FET, Gurukul Kangri University, Haridwar, Uttarakhand, India

\section{CH R O N I C L E A B S T RACT}

Article history:

Received: February 1, 2017

Received in revised format:

March 16, 2017

Accepted: May 17, 2017

Available online:

May 17, 2017

Keywords:

Six-Sigma

Manufacturing firm

Statistical approach

Sigma level

Process capability

\begin{abstract}
Six-Sigma is a statistical attitude - not judgment or sentiment. It is about statistical facts that assist the authorities to spotlight their concentration on the progression arrangement rather than on individuals and get assessments based on reality and unbiased information but not on impracticable prospects. Six-Sigma is an integrated approach to involve everything within the organization for reducing defects and variation. It is a combination of all efforts in an association for quality enhancement, quality progress and quality protection to reach the optimum clients satisfaction. The primary objective of Six-Sigma methodology is always directed towards the perfection at any level whether financial or non-financial. Putting efforts rightly and maintaining consistency are the basic concepts behind successful implementation of Six-Sigma. The present work provides a way to examine the Six-Sigma practice in a manufacturing firm with the use of statistical thinking in getting high quality products by reducing the variation and ultimately increasing profit.
\end{abstract}

\section{Introduction}

In today's fluctuating economic drift, industries whether manufacturing or service are working towards continuous improvement of their inherited processes to achieve customer delight. This can be achieved by inputting the continuous effort in understanding the process and managing the system associated with the process (Kaushik \& Mittal, 2017). In order to achieve customer satisfaction researchers and industrialists around the world have worked over various tools and techniques like Total Quality Management (TQM), Quality circles (Mittal and Prajapati 2014), APQP (Mittal et al., 2012; Mittal, Khanduja; Kaushik et al., 2011), Shainin system (Mittal et al., 2017), Quality Awards, Fuzzy logic (Mittal et al., 2016a), Total Preventive Maintenance (TPM), Business Process Reengineering (Mittal et al., 2016b), Lean and Six Sigma (Kaushik et al., 2012; Kaushik et al., 2016). One of the most popular techniques named above is Six-Sigma. It aims to find out the basic causes in process and eliminate them to achieve business excellence (Kaushik et al., 2016). The procedure includes the formation of team within the organization and using statistics along with traditional quality control tools (Kaushik \& Mittal, 2015). Six-Sigma is known as an influential methodology, which improves product/service 
quality in many industries around the world (Kaushik et al., 2008). It attacks toward the attitudinal change by its unique effective and efficient problem solving methodology (Kaushik \& Khanduja 2008).

In this study, a research has been undertaken to implement Six-Sigma technique to a small fasteners manufacturing unit situated in Haryana (India). The company manufactures a wide variety of fasteners which are distributed throughout various overall equipment manufacturing (OEMs) such as Bajaj Automotive, Hero Honda, Maruti Suzuki, Ford, Escort, etc. As a requirement of being the vendor organization of such big giants, the firm has to curb the high rejection rate and maintain a sound productivity level in its premises. Six-Sigma has proven potential in such cases (Kaushik 2011). In our perspective, the implementation of Six-Sigma in a small company is easier as management support and commitment are readily available, as contrary to big firms (Biswas \& Chowdhury, 2016).

\section{Manufacturing Firm - A Case Study}

The current research was performed in a fastener producing industry located in Haryana, India. Concerned firm manufactures a wide variety of fasteners which are distributed throughout various major firms such as Bajaj Automotive, Hero Honda, Maruti Suzuki, Ford, etc. The specialized product of the firm is shoulder bolt where no other firm is manufacturing in the industrial range. So, major automotive firms depend heavily on this fastener manufacturing firm for shoulder bolt supply.

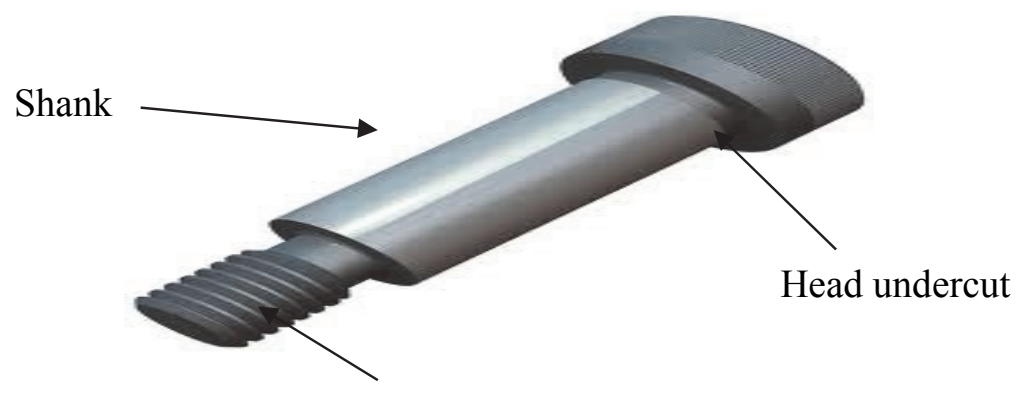

Thread undercut

Fig. 1. Pictorial View of Shoulder Bolt

Taking into account the importance of the product, initial observations were carried out which shows a continuously increasing trend of rejection in production of shoulder bolt. The rejection of shoulder bolt was very high due to the large variations in thread undercut diameter of shoulder bolt. The pictorial view of shoulder bolt is shown in Fig. 1.

Observing such a high rejection rate, quality control team showed a keen interest in improving the process of the concerned product. So, in the present study DMAIC methodology of Six-Sigma is deployed by studying and analyzing the shoulder bolt rejection problem.

\subsection{Execution of Six-Sigma DMAIC Methodology}

DMAIC Methodology of Six Sigma was implemented sequentially i.e. applying each phase one by one so as to improve the production process of the Shoulder Bolt. The phase wise description of DMAIC Methodology is explained below.

\subsubsection{Define}

This phase is all about turning the customer expectations into the product. The objective of the project/problem should be clearly defined along with the necessary explanation. This lays down the correct foundation of any task because improvement can only be made if the problem is defined in a proper way. For this purpose, in the present case, a Supplier, Input, Process, Output, Customer (SIPOC) diagram (Fig. 2), Process Map (Fig. 3) and Tree Diagram for CTQ factors (Fig. 4) was drawn which helped in documenting the operational sequence of shoulder bolt and to recognize the area for maximum scope for improvement. The CTQ factors lead us to work on the targeted area and hence are considered as very important part of project. A number of brainstorming sessions were held to list CTQ characteristics 
considering customer input. As the aim of this phase was to identify the root cause of problem, CTQs of the shoulder bolt rejection were determined with the help of tree diagram.

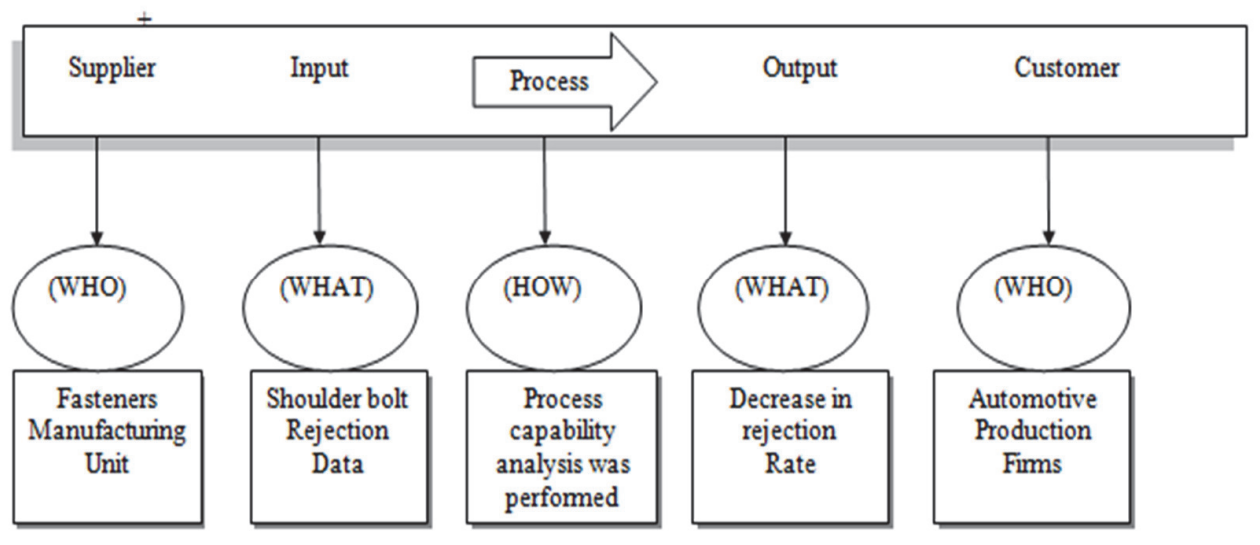

Fig. 2. SIPOC Diagram

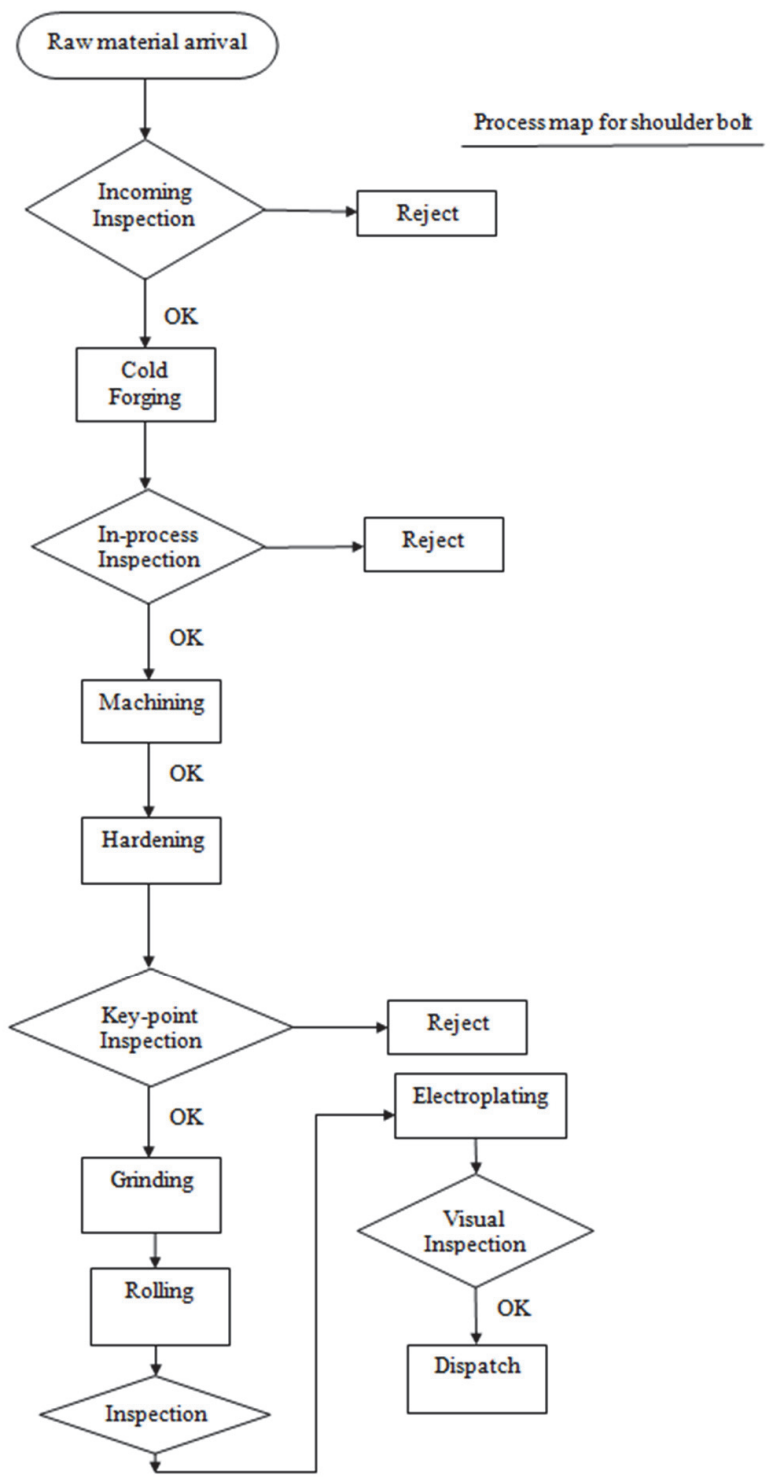

Fig. 3. Process Map for Shoulder Bolt 


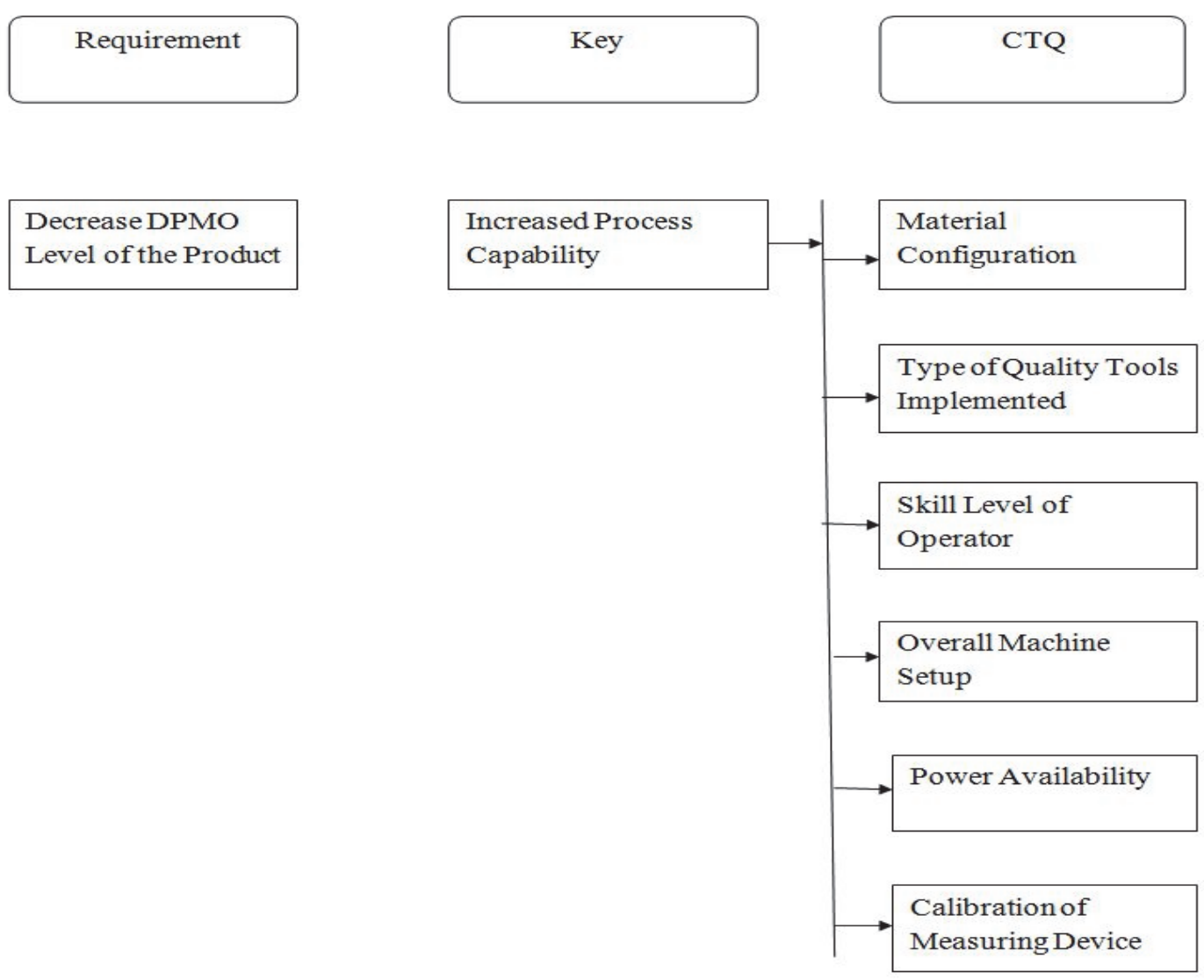

Fig. 4. Tree Diagram for CTQ Factors Regarding Shoulder Bolt Rejection

\subsubsection{Measure}

In this phase a measure of the current status of the problem is made. Also it is assured that the problem is of dissociate nature i.e. there should not be any hidden cause associated with the problem that are not concerned with the manufacturing process. One of these causes may be the wrong measurement of parts. Hence a check at the measurement system is also made in this phase. The measurement system analysis (MSA) measures the authenticity of the measuring instrument used in the firm. In MSA, gauge repeatability and reproducibility $(\mathrm{R} \& \mathrm{R})$ study are performed. The gauge used in this case is a micrometre. The study included the readings from two operators on the same gauge. The sample size was ten and two readings were taken on each sample, thereby making a total of 40 readings.

The results of Gauge R\&R study when inputted in the Minitab software showed, repeatability and reproducibility levels at 28.04 percent and 0.00 percent. According to the standard if the percentage study variation is less than 30 percent then the gauge can be termed as correct and MSA showed no conflict on the measurement part.

\subsubsection{Analysis}

Analysis phase of the methodology is a structured phase to examine the collected data to find how well the process is going on and the causes of variation.

\section{a) Process capability analysis}

Process capability analysis was done to calculate the present state of the manufacturing process. Minitab software was used and results are shown in Fig. 5. Cpk comes out to be $0.58, \mathrm{Z}-$ Bench sigma value was found to be 1.39 and existing DPMO level of the process comes out to be $82,572.51$. The DPMO level was very high and showed that huge improvement is needed in the process. 


\section{Process Capability Analysis for thread undercut diameter}

\begin{tabular}{lr}
\multicolumn{2}{c}{ Process Data } \\
LSL & 7.42000 \\
Target & 7.48500 \\
USL & 7.55000 \\
Sample Mean & 7.48490 \\
Sample N & 100 \\
StDev(Within) & 0.03744
\end{tabular}

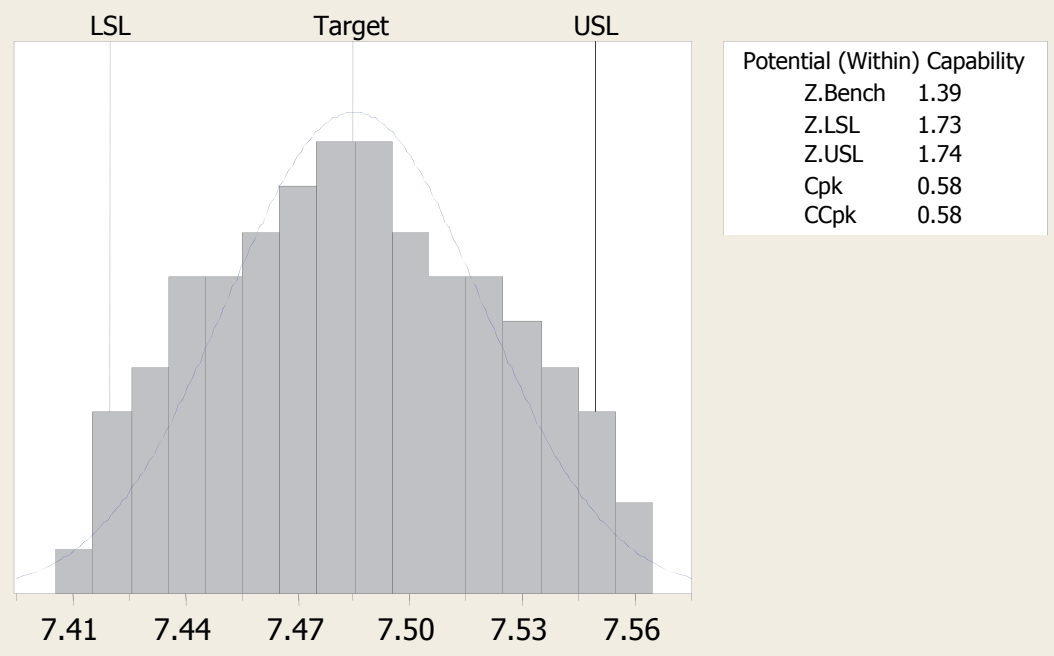

Exp. Within Performance

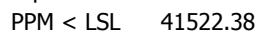

Fig. 5. Process Capability Analysis for thread undercut diameter

\section{b) Fishbone Diagram}

A fishbone diagram is a famous quality tool used for listing the possible root causes in the process due to man, machine, method and material. This tool was used to identify the cause of the problem of shoulder bolt rejection by applying the experience and expertise as shown in Fig. 6 .

After concentrating on possible root causes associated with the process, hypotheses were formed and checked using two sample t-test. This helped in narrowing the list of possible causes of variations. Two sample t-test was chosen because of its usage in the similar conditions and also it was easy to be applied. Also the results of the t-test are very much reliable. Following are the result of t-test applied on operator skill, collet movement, hydraulic pressure variation and spring stiffness.

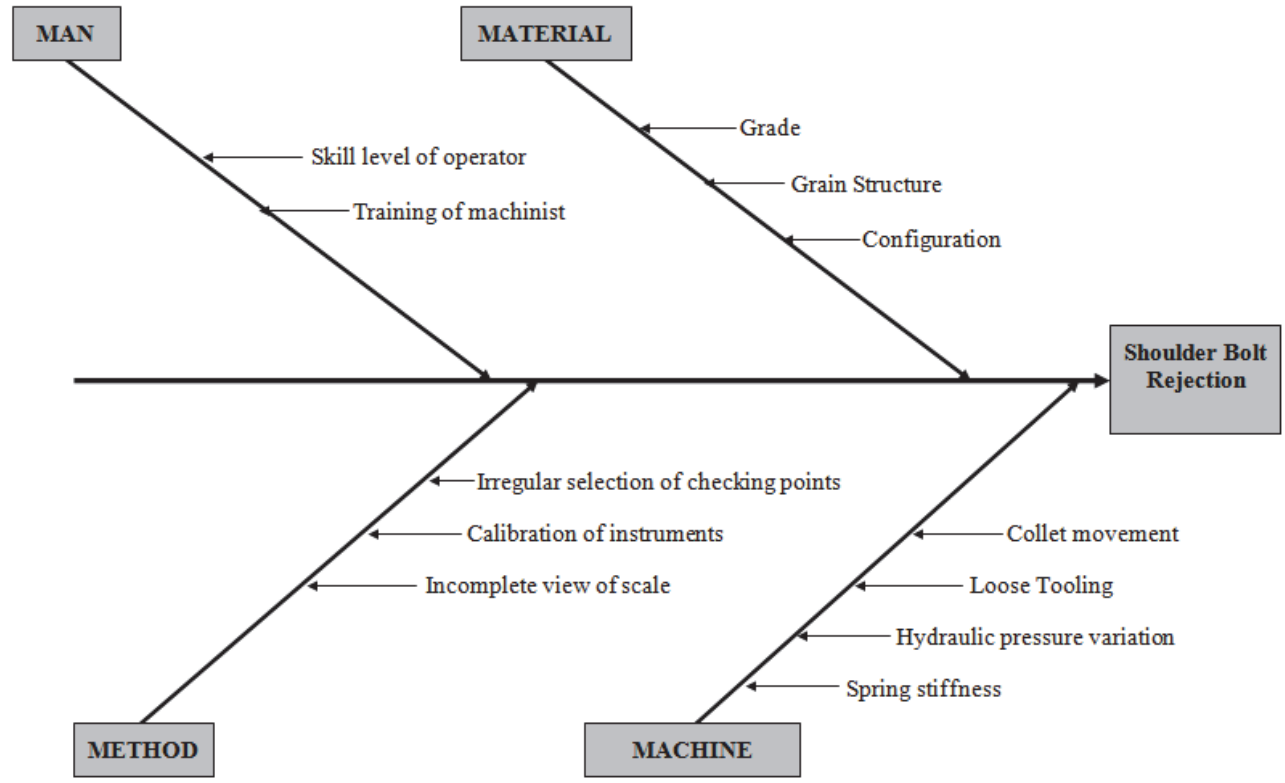

Fig. 6. Fishbone diagram 
c) Two-sample t-test

Case-1: The result of t-test for operator skill (skilled and unskilled) showed that the p-value for thread undercut diameter was $>0.05$, hence operator skill was not a cause for shoulder bolt rejection.

Case-2: The result of t-test for collet movement showed that the p-value for thread undercut diameter was $>0.05$, hence operator skill was not a cause for shoulder bolt rejection.

Case-3: The result of t-test for hydraulic pressure variations showed that the $\mathrm{p}$-value for thread undercut diameter was $<0.05$, hence operator skill was a cause for shoulder bolt rejection.

Case-4: The result of t-test for spring stiffness showed that the p-value for thread undercut diameter was $<0.05$, hence operator skill was a cause for shoulder bolt rejection.

\subsubsection{Improve}

In this phase, recommendations are made out of root causes to improve the process. In present case study, Design of Experiments was performed to calculate the optimum conditions of the causes shortlisted in analyze phase. The experiments were piloted to optimize the value of hydraulic pressure and spring stiffness. A $2 \times 2$ array was used, i.e. each factor at each level. Table 1 shows the optimum values of each parameter for thread undercut diameter variation.

\section{Table 1}

Significant vital factors for thread undercut diameter variations

\begin{tabular}{lll}
\hline Vital factors & Low level & High level \\
\hline Hydraulic pressure variations & $22 \mathrm{~h}$ & $12 \mathrm{~h}$ \\
Spring stiffness & $22 \mathrm{~h}$ & $12 \mathrm{~h}$ \\
\hline
\end{tabular}

Further, Minitab was used to calculate the effect and interaction among parameters by plotting main effects and interaction plot. Table 2 shows the results of each experiment.

It is evident from main effect plot as shown in Fig. 7 that hydraulic pressure variation is a negligible factor and spring stiffness is a main factor.

Parallel lines can be seen in interactions plot Fig. 8, which indicates that there are no interactions existing between the factors.

\section{Table 2}

Readings of significant factors at various levels

\begin{tabular}{cccc}
\hline S. No. & Hydraulic pressure variations & Spring stiffness & Readings thread undercut diameter (mm) \\
\hline 1 & After 22 h & After 22 h & 7.478 \\
2 & After 12 h & After 12 h & 7.466 \\
3 & After 22 h & After 22 h & 7.48 \\
4 & After 12 h & After 12 h & 7.475 \\
5 & After 22 h & After 22 h & 7.492 \\
6 & After 12 h & After 12 h & 7.485 \\
7 & After 22 h & After 22 h & 7.512 \\
8 & After 12 h & After 12 h & 7.452 \\
\hline
\end{tabular}




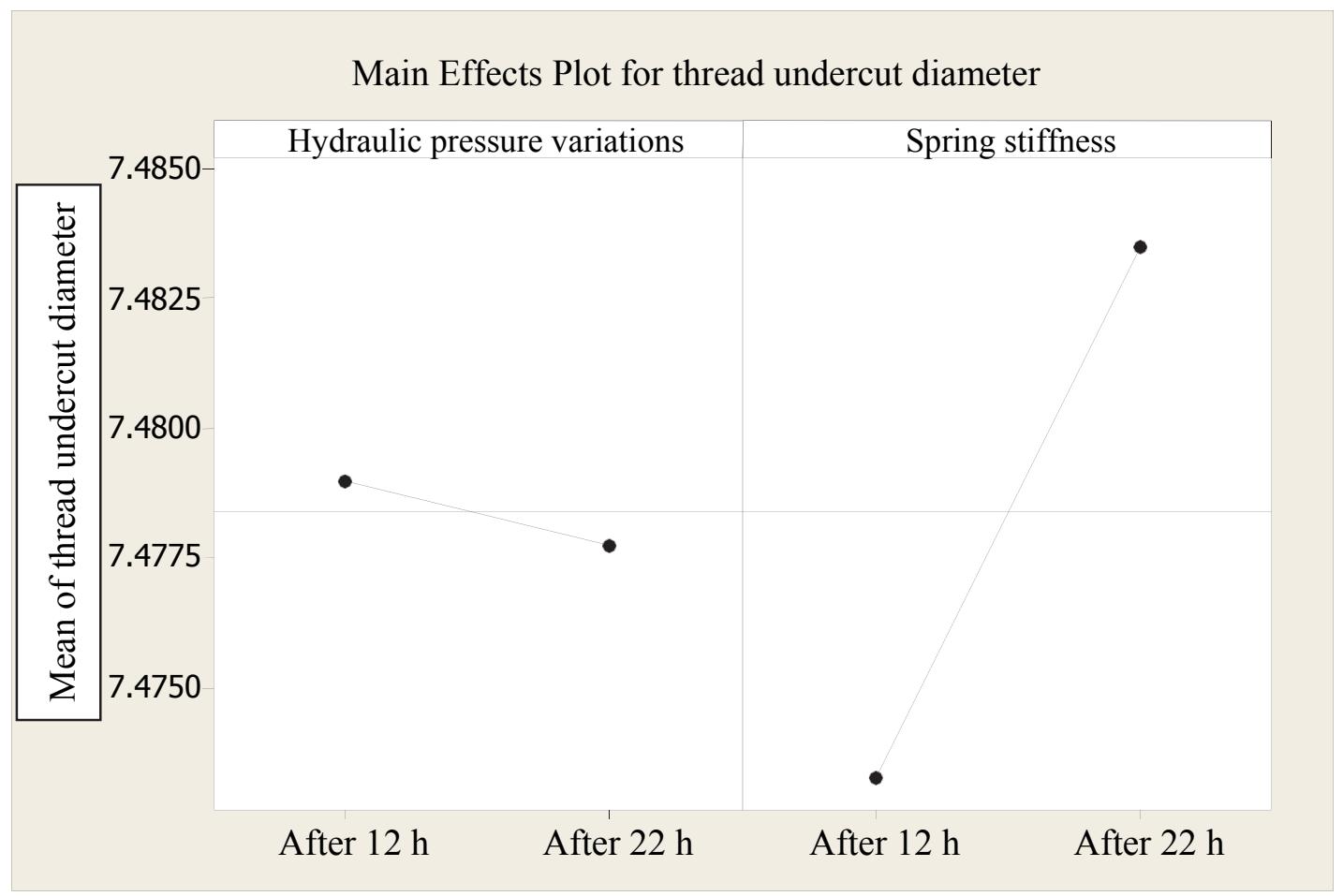

Fig. 7. Main Effects Plot for Thread Undercut Diameter

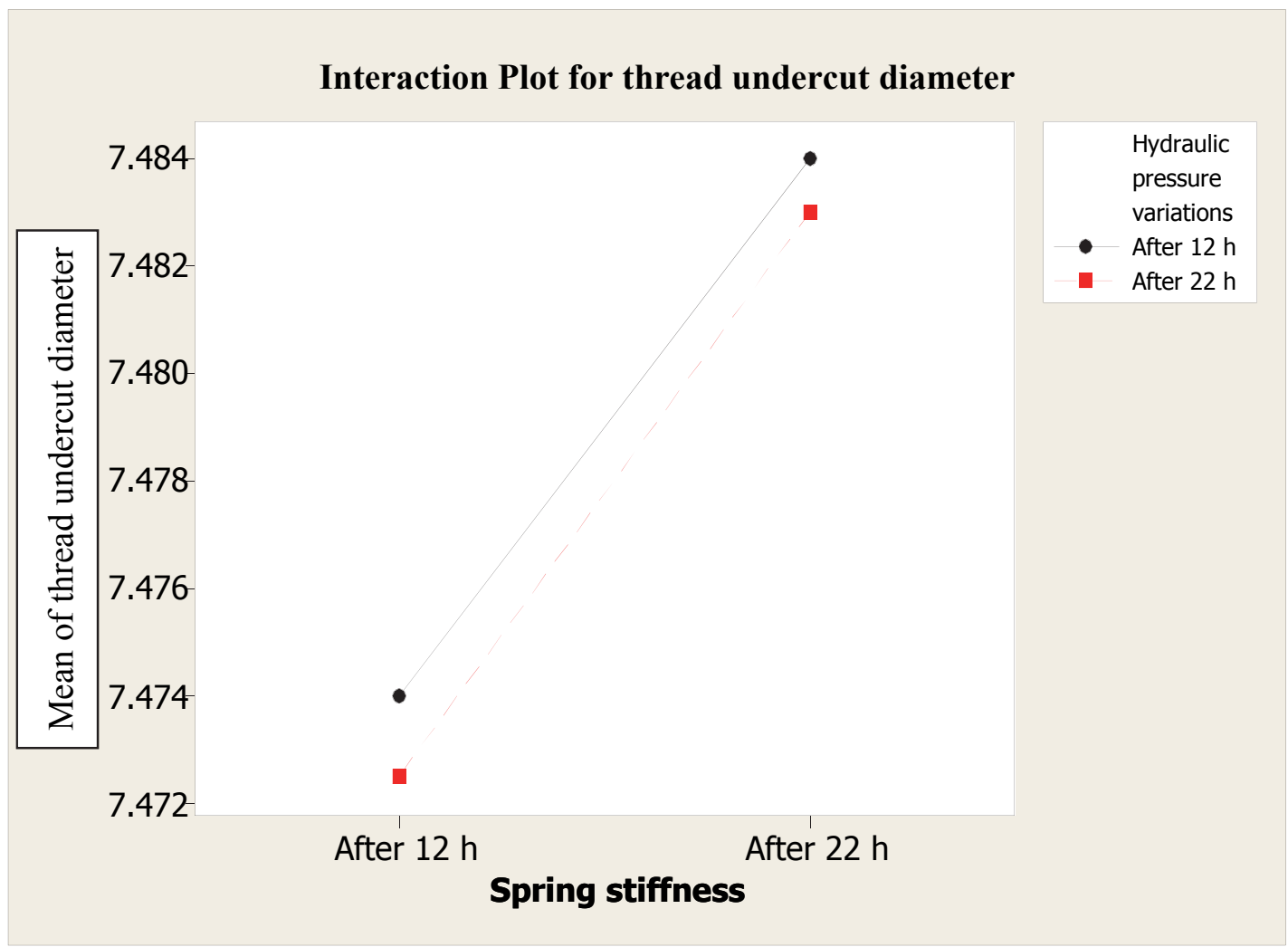

Fig. 8. Interaction Plot for Thread Undercut Diameter

\subsubsection{Control}

This phase is designed under Six-Sigma methodology to monitor the effects of implementation made for each recommendation. Also the monitoring is continued to a prolonged period of time to see the 
long term aftereffect if any. Here in this case, $\bar{X} / \mathrm{R}$ control chart (Fig. 9) was drawn to see the existence of assignable causes.

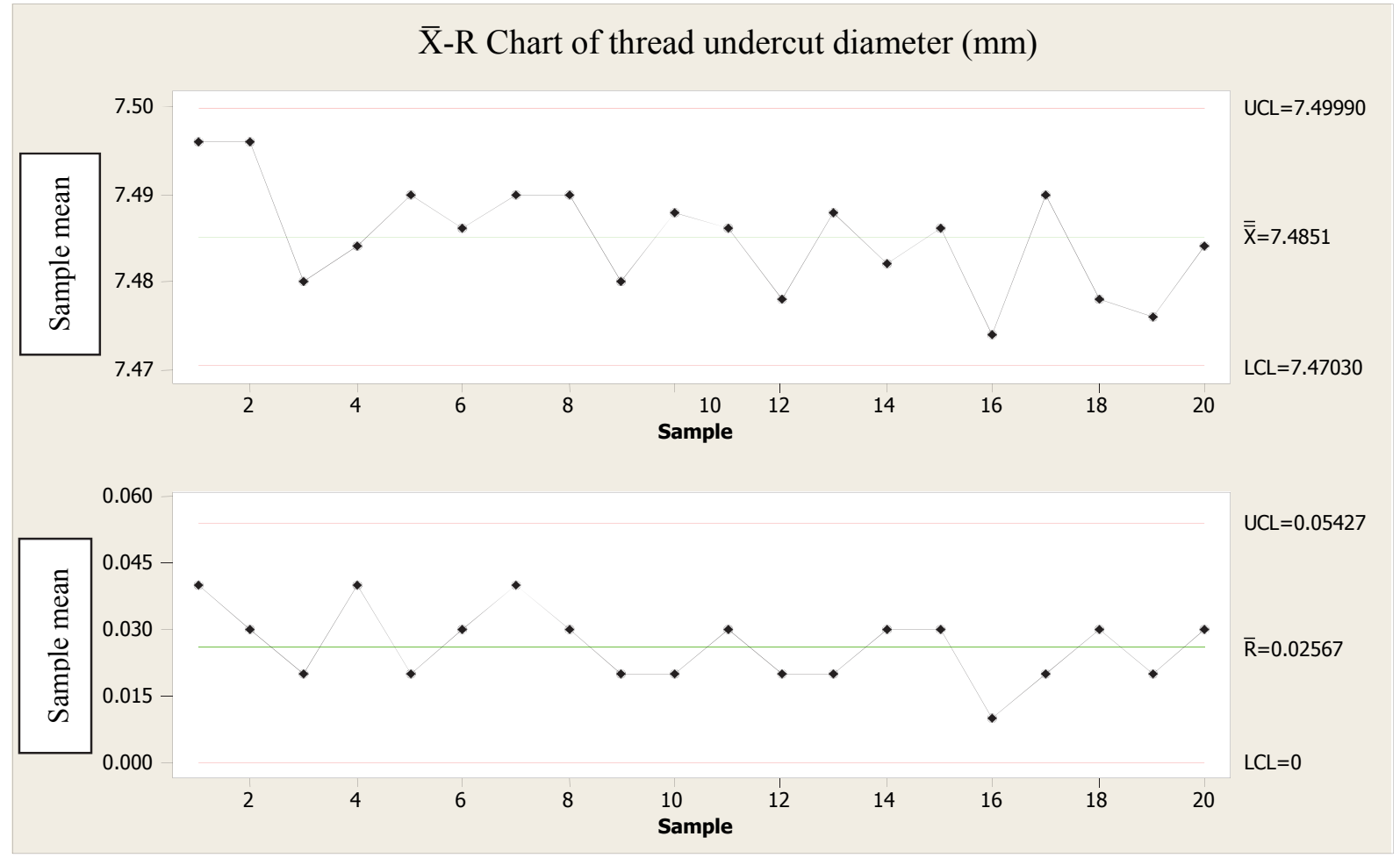

Fig. 9. $\bar{X}-R$ Chart of Thread Undercut Diameter (mm)

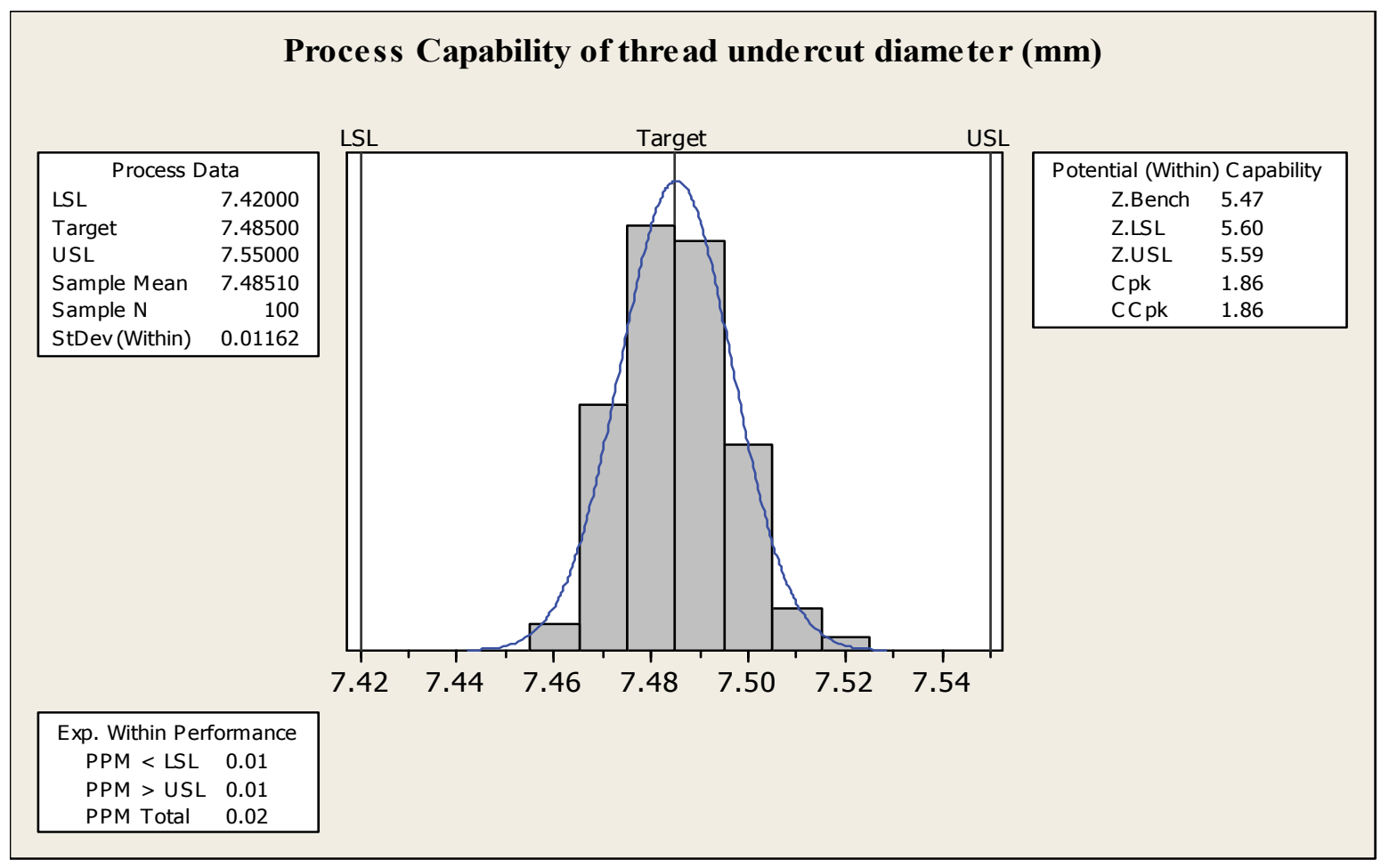

Fig. 10. Process capability analysis of thread undercut diameter after Improvement 


\section{Results \& Discussion}

As a result of the Six-Sigma approach implementation, the process capability was improved to 1.86 and the Z-bench sigma level was increased up to 5.47 (Fig. 10) from a meagre value of 1.39, resulting in decreased shoulder bolt rejection DPMO to 0.02. Anything below 3.4 DPMO is considered as successful Six-Sigma implementation so the project was said to be successful. Additionally, the financial benefit of this study was approximately US $\$ 90,079$ per annum. In addition to these results, better process knowledge and use of statistical thinking to solve manufacturing problems was also attained, which will serve extremely beneficial for the organization in the near future.

\section{Conclusion}

Impression of Six Sigma implementation insists us to consider Six Sigma approach - a profit boosting approach. Six-Sigma implementation in manufacturing and process industry targets at improving the process performance and at reducing the defects by minimizing the variation inherent in the process or product. Application of Six Sigma seems to have a practical approach whereas the other quality improvement approaches seems to be theoretical. Statistical thinking of Six Sigma approach makes it more real and practical. In this case study, Six-Sigma application brought up the Cpk level and PPM to acceptable limits. The profit earned by organization could be further utilized for other quality and energy saving projects which multiplied the confound effect of Six-Sigma implementation. It is a small step towards implementing the Six Sigma project to these types of small firms which will provide the documented evidence to other such firms and will motivate them.

\section{Acknowledgement}

The authors would like to thank the anonymous referees for constructive comments on earlier version of this paper.

\section{References}

Biswas, S., \& Chowdhury, B. (2016). Industrial Applications and Practices of Six Sigma-A Literature Review. Sigma, 3(3), 176-79.

Kaushik, P. (2011). Relevance of Six Sigma Line of Attack in SMEs: A case study of a die casting manufacturing unit. Journal of Engineering and Technology, 1(2), 107.

Kaushik, P., Grewal, C. S., Bilga, P. S., \& Khanduja, D. (2008). Utilising Six Sigma for energy conservation: a process industry case study. International Journal of Six Sigma and Competitive Advantage, 4(1), 18-34.

Kaushik, P., \& Khanduja, D. (2008). DM make up water reduction in thermal power plants using Six Sigma DMAIC methodology. Journal of Scientific and Industrial Research, 67(1), 36-42.

Kaushik, P., Khanduja, D., Mittal, K., \& Jaglan, P. (2012). A case study: Application of Six Sigma methodology in a small and medium-sized manufacturing enterprise. The TQM Journal, 24(1), 416.

Kaushik, P., \& Mittal, K. (2015). Significance of Six Sigma Basics in a Manufacturing Unit: A Case Study." Progress in Management Sciences 3(1).

Mittal, K., \& Kaushik, P. (2017). A general model for problem solving in manufacturing or service organizations. Journal of Engineering and Technology, to appear.

Kaushik, P., Mittal, K., \& Rana, P. (2016). Energy paybacks of six-sigma: A case study of manufacturing industry in India. Management Science Letters, 6(11), 691-700.

Mittal, K., Kaushik, P., \& Khanduja, D. (2012). Evidence of APQP in quality improvement: An SME case study. International Journal of Management Science and Engineering Management, 7(1), 20 28.

Mittal, K., Dinesh K., \& Kaushik, P. (2011). Leveraging APQP methodology to drive improvement in SME : A case study. International Journal of Contemporary Practices, 1(1), 38-51. 
Mittal, K., \& Prajapati, R. K. (2014). Quality councils: an overview. International Journal of Management, IT and Engineering, 4(12), 200.

Mittal, K., Tewari, P. C., \& Khanduja, D. (2016a). Refurbishing Business Processes: An Insight. Journal of Industrial Engineering and Advances, 1(1), 1-8.

Mittal, K., Chandra Tewari, P., Khanduja, D., \& Kaushik, P. (2016b). Application of Fuzzy TOPSIS MADM approach in ranking \& underlining the problems of plywood industry in India. Cogent Engineering, 3(1), 1155839.

Mittal, K., Tewari, P. C., \& Khanduja, D. (2017). Productivity improvement under manufacturing environment using Shainin system and fuzzy analytical hierarchy process: a case study. The International Journal of Advanced Manufacturing Technology, 1-15.

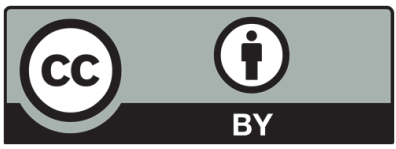

(C) 2017 by the authors; licensee Growing Science, Canada. This is an open access article distributed under the terms and conditions of the Creative Commons Attribution (CC-BY) license (http://creativecommons.org/licenses/by/4.0/). 